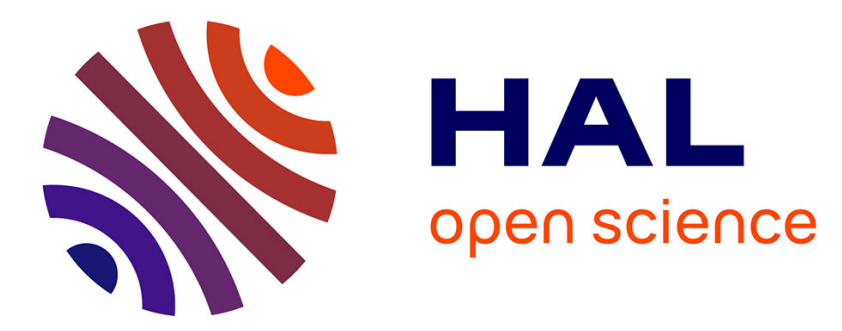

\title{
Grafting of gold onto spin-crossover nanoparticles: $\mathrm{SCO} @ \mathrm{Au}$
}

Lucie Moulet, Nathalie Daro, Stéphane Mornet, Noelia Vilar-Vidal, Guillaume

Chastanet, Philippe Guionneau

\section{> To cite this version:}

Lucie Moulet, Nathalie Daro, Stéphane Mornet, Noelia Vilar-Vidal, Guillaume Chastanet, et al.. Grafting of gold onto spin-crossover nanoparticles: SCO@Au. Chemical Communications, 2016, 52 (90), pp.13213-13216. 10.1039/C6CC05708J . hal-01395082

\section{HAL Id: hal-01395082 \\ https://hal.science/hal-01395082}

Submitted on 2 Mar 2021

HAL is a multi-disciplinary open access archive for the deposit and dissemination of scientific research documents, whether they are published or not. The documents may come from teaching and research institutions in France or abroad, or from public or private research centers.
L'archive ouverte pluridisciplinaire HAL, est destinée au dépôt et à la diffusion de documents scientifiques de niveau recherche, publiés ou non, émanant des établissements d'enseignement et de recherche français ou étrangers, des laboratoires publics ou privés. 


\section{Journal Name}

\section{Graft of gold on spin-crossover nanoparticles: SCO@Au}

Received 00th January 20xx, Lucie Moulet, ${ }^{a}$ Nathalie Daro, ${ }^{a}$ Stéphane Mornet, ${ }^{a}$ Noelia Vilar-Vidal, ${ }^{a}$ Guillaume Chastanet $^{\mathrm{a}}$ and Philippe Guionneau*a

Accepted 00th January 20xx

DOI: $10.1039 / \times 0 \times x 00000 x$

www.rsc.org/

Nanoparticles of gold were successfully directly grafted on nanoparticles of a 1D polymeric Spin-CrossOver material leading to singular SCO@Au hybrid particles. The result is equally obtained using a large panel of gold-particles sizes, from 4 to $45 \mathrm{~nm}$, which first allows defining the best experimental conditions, notably in term of gold-particles concentration, and then demonstrates the robustness and the efficiency of the method.

The Spin-CrossOver (SCO) phenomenon currently attracts many attention from diverse scientific communities and in particular the chemists' one. ${ }^{1}$ This craze for the SCO materials notably comes out since their development process has now reach the step where fundamental questioning can be accompanied with more practical concerns, the latter being announced for decades. ${ }^{2}$ Among them is the examination of the routes to design functionalized SCO nanoparticles. Getting SCO nano-particles is now a common and relatively easy task, ${ }^{3}$ notably with triazol-based iron materials, ${ }^{3 c-8}$ but their functionalization is still under investigation; one of the main targets being the discovery of new photophysical properties and new SCO nanomaterials to reduce the required laser power to get a complete spin state switching. In this context, the achievement admitted as being one of the most challenging is to graft gold nanoparticles (AuNPs) on polymeric triazol-based iron(II) complexes nanoparticles. ${ }^{2 \mathrm{~d}, 4,5}$ To this aim, the prevalent investigated route consists in wrapping the SCO particles with silica prior to attempt to fix the gold particles. Recently, this route was shown to be achievable by different research groups. ${ }^{5}$ However the strategy used was a multistep process of coating and surface functionalization by silanization for the anchoring of gold. This latter step notably has to be optimized to improve the surface density of anchoring functions (such as amines or thiol) and to increase the density of fixed AuNPs on a SCO particles. Despite this, some pioneer studies evidenced that

a. CNRS, Univ. Bordeaux, ICMCB, UPR 9048, 87 avenue du Dr A. Schweitzer, F-33608 Pessac, France

*Contact author: philippe.guionneau@icmcb.cnrs.fr

Electronic Supplementary Information (ESI) available: initial characterization of [Fe(Htrz) $(\mathrm{trz}]\left(\mathrm{BF}_{4}\right)$ particles (magnetism, PXRD, TEM), initial characterization of gold nanoparticles (TEM, spectroscopies), magnetic measurements and STEM EDX for $\left[\mathrm{Fe}(\mathrm{Htrz})_{2}(\mathrm{trz})\right]\left(\mathrm{BF}_{4}\right) @$ AuNPs, details of the calculation of $n$ used to define the Au:SCO ratio. See DOI: 10.1039/x0xx00000x the presence of gold particles has opened some promising perspectives for new physical properties in SCO materials, including plasmonic effects. ${ }^{2,6}$ The development of a more robust method to increase the amount of AuNPs onto the surface of SCO NPs in order to modulate their SPR property is still a challenge. We present here a new route to efficiently fix gold particles on SCO particles in a simple manner. The starting idea was to attach the gold particle directly to the SCO one, without the need of a silica coat but by taking advantage of the likely affinity of the coordination ligand for Au. Note that this idea was already mentioned a few years ago but in this case the grafting was not clearly evidenced - probably due to some intrinsic properties of the chosen SCO compound - and no further experiments were thus attempted. ${ }^{7}$ Here, the compound chosen to test the concept of the direct gold-grafting appears to be one of the most studied within the scientific community and in any case the one always cited when referring to the high potential of application of the SCO materials. This compound is the 1D-polymeric iron(II) compound of formula $\left[\mathrm{Fe}(\mathrm{Htrz})_{2}(\operatorname{trz})\right]\left(\mathrm{BF}_{4}\right)(\mathrm{Htrz}=1 \mathrm{H}-1,2,4$-triazole and $\operatorname{trz}=$ deprotonated triazolato(-) ligand) undergoing a SCO with a wide hysteresis above the room temperature $\left(T_{1 / 2}=346-375 \mathrm{~K}\right){ }^{5,8}$ The particles are of good crystalline quality, allowing the determination of HS and LS crystal structures, whatever the particle sizes. ${ }^{9}$

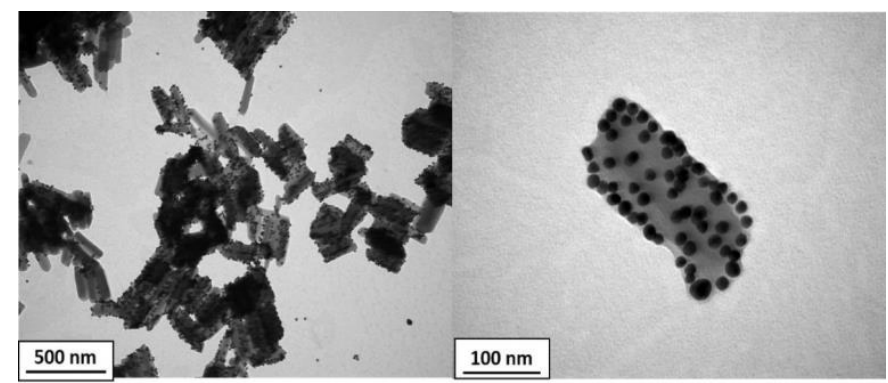

Fig. 1 TEM images of $\left[\mathrm{Fe}(\mathrm{Htrz})_{2}(\mathrm{trz})\right]\left(\mathrm{BF}_{4}\right) @$ AuNPs with $10 \mathrm{~nm}$ gold particles. View of a batch (left) and focus on one singular particle (right). STEM EDX images confirm the nature of the particles (available in the ESI). 

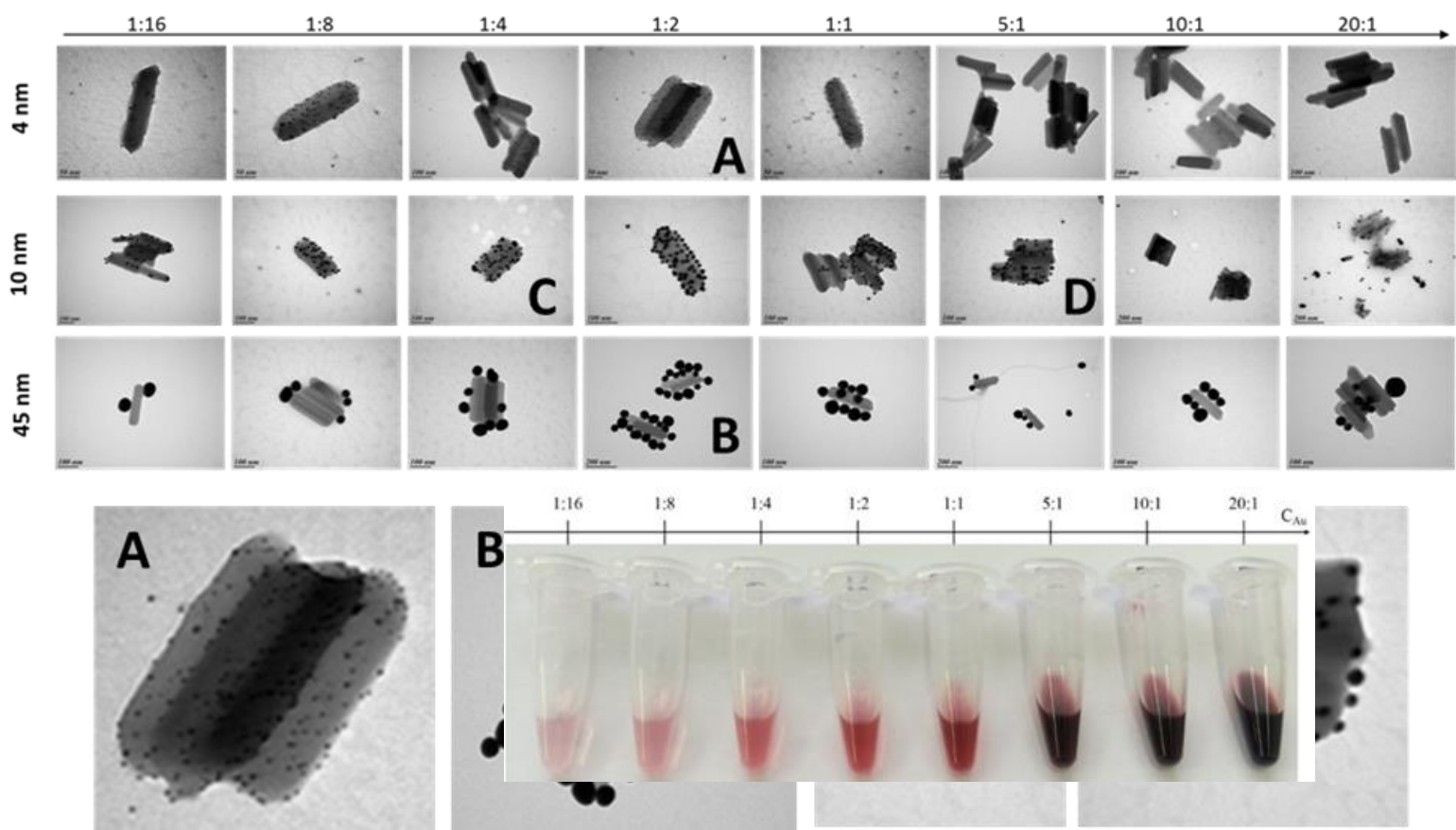

The synthesis of the nanoparticles of this compound is a well-known process including recent progress on micellar methods allowing a perfect control of the size of the particles.5,9a All the $\left[\mathrm{Fe}(\mathrm{Htrz})_{2}(\mathrm{trz})\right]\left(\mathrm{BF}_{4}\right)$ particles synthesized here present a morphology of rods with average dimensions of $\sim 200 \mathrm{~nm}$ long and $\sim 60 \mathrm{~nm}$ large. While this same size of SCO particles was used all along this work, a panel of spherical gold-particles was tested with diameters of $4 \mathrm{~nm}$, $10 \mathrm{~nm}$ and $45 \mathrm{~nm}$. The gold NPs were synthesized by using previous published protocols ${ }^{10}$. Subsequently, surface modification of the assynthesized AuNPs were carried out by using a PVP polymer $(\mathrm{Mw}=55000)$. Note that the quality of the gold-particle synthesis already appears as a key point for the subsequent grafting efficiency. The assemblage of the SCO and gold particles is then performed as following described. Initially, $50 \mu \mathrm{L}$ of gold nanoparticles $(10 \mathrm{~nm})$ at the concentration of $8.1510^{16}$ part/L is mixed to $50 \mu \mathrm{L}$ of ethanol in a microtube of $1.5 \mathrm{~mL}$. Then, $100 \mu \mathrm{L}$ of a solution of $\left[\mathrm{Fe}(\mathrm{Htrz})_{2}(\mathrm{trz})\right]\left(\mathrm{BF}_{4}\right)$ at $0.18 \mathrm{~g} / \mathrm{L}$ is added and mixed at room temperature during one night. The final product is washed with an ethanolic solution of PVP in order to maintain the colloidal stability. The result is presented on Fig. 1. The grafting of AuNPs appears

To monitor the effects of the initial gold-concentration on the final result, we define here the ratio Au:SCO. The notation 1:1 describes the situation where the $n$ gold nanoparticles necessary to theoretically cover entirely one $\mathrm{SCO}\left[\mathrm{Fe}(\mathrm{Htrz})_{2}(\mathrm{trz})\right]\left(\mathrm{BF}_{4}\right)$ particle are used. For instance, the ratio $5: 1$ means that $5 n$ gold nanoparticles are used while 1:4 means only one quarter of the $n$ gold nanoparticles are used (details of calculation are provided in ESI). The first synthesis reported above corresponds therefore to the ratio 1:2. Note also that $n$ is obtained from the relative values of the surfaces calculated from the dimensions of the SCO and gold-particles. For instance, for $10 \mathrm{~nm}$ gold-particles, $n$ corresponds to 500 particles. With this definition, the ratios going from 1:16 to 20:1 were investigated (Fig. 2). With evidence, the amount of AuNPs fixed on the SCO particles making hybrid $\left[\mathrm{Fe}(\mathrm{Htrz})_{2}(\operatorname{trz})\right]\left(\mathrm{BF}_{4}\right) @$ AuNPs particles gradually increases according to the initial committed concentration of gold.

Fig. 2 View of the different tubes containing the $\left[\mathrm{Fe}(\mathrm{Htrz})_{2}(\operatorname{trz})\right]\left(\mathrm{BF}_{4}\right) @ A u N P s$ particles obtained with $10 \mathrm{~nm}$ AuNPS and a panel of initial concentration going from 1:16 to 20:1. See text for definition.

Fig. 3 View of the hybrid [Fe(Htrz) $2(\operatorname{trz})]\left(\mathrm{BF}_{4}\right) @$ AuNPs particles shown as a function of the Au concentration-ratio (from 1:16 to 20:1; see text for definition) and of the gold particle size $(4,10$ and $45 \mathrm{~nm}$ ) from TEM. Zoom on four samples selected out of the whole panel. 


\section{Journal Name}

\section{COMMUNICATION}

In addition to the $10 \mathrm{~nm}$ gold-particles, we tested also this method using $4 \mathrm{~nm}$ and $45 \mathrm{~nm}$ gold-particles. As a result, an overview of the formation of the hybrid $\left[\mathrm{Fe}(\mathrm{Htrz})_{2}(\operatorname{trz})\right]\left(\mathrm{BF}_{4}\right) @ \mathrm{Au}$ particles is given not only as a function of the gold initial concentration but also for three gold-particle sizes (Fig. 3). The fixation of gold on the SCO particles observed in all situations shows different grafting qualities (Fig. 3). First, even though it appears challenging to quantify, a simple observation of the TEM images clearly evidence that at high initial concentrations of gold nanoparticles (from 5:1 to 20:1) the grafting is poorly efficient with a very low number of fixed gold particles on the SCO ones. On the contrary, low initial concentrations (from 1:8 to $1: 1$ ) result in a large number of gold particles covering the SCO ones which allows defining this concentration range as the optimal experimental conditions. Note that the complete covering, theoretically reached for $1: 1$, is never obtained and that the best grafting ratio seems to be rather obtained for the 1:2 experimental conditions. Interestingly, the same conclusions are reached whatever the gold-particle sizes which validates the present route for grafting gold on these SCO particles. Even if the adhesion mechanism still remains poorly understood, the origin of gold-grafting on $\left[\mathrm{Fe}(\mathrm{Htrz})_{2}(\mathrm{trz})\right]\left(\mathrm{BF}_{4}\right)$ could be assigned to the presence of the nitrogen donor atoms present in triazole molecules at the surface of SCO particles which coordinate the metal surface site of the AuNPs. ${ }^{11}$ This hypothesis is supported by zeta potential measurements performed on gold nanoparticles stabilized with different types of ligands (weak ones such as citrate and PVP, and a stronger amphiphilic ligand, CTAB (cetyltrimethylammonium bromide) which stabilizes the dispersion by forming a bilayer surrounding the NPs) (see ESI). Whatever the ligand type, it can be obviously observed the exchange manifested by the tendency of three potential profiles to tend towards the same potential value around $-10 \mathrm{mV}$ for saturating concentrations. The grafting kinetic of gold on SCO is slow, that is the reason why the dispersions are incubated overnight. PVP macromolecules are chemisorbed by exchange reaction of citrate ligands by non-bonding electron transfer from the $\mathrm{O}$ atom of the pyrrolidone ring of PVP molecules to the electron deficient Au surface sites (M. Behera and S. Ram International Nano Letters 2013, 3:17). The stabilization of the gold dispersions results from a dynamic equilibrium between chemisorbed and free macromolecules remaining in the medium. When the amount of free PVP macromolecules decrease, the colloidal destabilization occurs. Therefore, it is mandatory to let an excess of free PVP, of more than $1 \mathrm{~g} / \mathrm{L}$ in order to maintain the colloidal stabilization (see Figure in ESI). The exchange reaction may be conditioned by the amount of free macromolecules by a law of mass action. That's the reason why we observe, in particular, a decrease of the number of gold particles by SCO for high concentrations of gold nanoparticles (Fig. 3, main text) which require higher amounts of PVP to stabilize the dispersion. The role of the PVP, used here as exchangeable stabilizing agent of gold dispersions, in the adhesion must be yet established in order to better understand this adhesion mechanism. The presence of the PVP macromolecules visible by TEM that covers the surface of the
[Fe(Htrz $\left.)_{2}(\operatorname{trz})\right]\left(\mathrm{BF}_{4}\right) @$ AuNPs is due to the drying state of the sample which concentrated the free polymer on their surface (Fig. 4).

Fig. 4 TEM images of SCO@Au nanografted particles for (right) 10 nm and (left) $45 \mathrm{~nm}$ gold particles.

Furthermore, SCO properties of the hybrid particles through

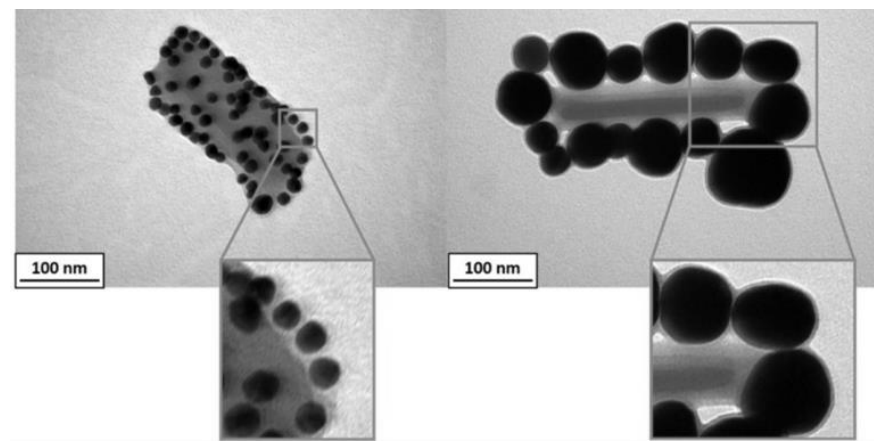

magnetic SQUID measurements were determined (see ESI). The SCO characteristics of $\left[\mathrm{Fe}(\mathrm{Htrz})_{2}(\operatorname{trz})\right]\left(\mathrm{BF}_{4}\right)$ appear not affected in comparison to the usual behaviour since no significant differences nor in the transition temperatures nor in the hysteresis width are observed $\left(\mathrm{T}_{1 / 2}=365 \mathrm{~K}, \Delta \mathrm{T}=18 \mathrm{~K}\right)$. Preliminary tests of the influence on the SCO features of lightening the hybrid SCO@Au particles were performed using a $510 \mathrm{~nm}$ laser source with increasing powers from 10 to $45 \mathrm{~mW} / \mathrm{cm}^{2}$. In these conditions, no noticeable effects are observed. More investigations are obviously required to deeply measure the impact of the grafting on the physical properties, notably the photomagnetic ones. To this aim, taking in mind that the synthesis of the hybrid SCO@Au particle must be first optimized to get larger amounts since the present results refer to $\mu \mathrm{L}$ quantities, it could be interesting to sublimate the present concept using larger gold particles (> $50 \mathrm{~nm}$ ) and powerful light sources.

\section{Notes and references}

‡ Transmission electron microscopy (TEM) images are acquired using a HITACHI H7650, with a high resolution mode and a tension of $60 \mathrm{kV}$.

$\S$ The synthesis of $\left[\mathrm{Fe}(\mathrm{Htrz})_{2}(\operatorname{trz})\right]\left(\mathrm{BF}_{4}\right)$ particles using micellar method was done as reported in the literature ${ }^{9 a}$ using the following parameters: concentration of $\mathrm{Fe}\left(\mathrm{BF}_{4}\right)_{2} .6 \mathrm{H}_{2} \mathrm{O}$ is fixed at $2 \mathrm{mmol} / 1.6 \mathrm{~g}$ and Tergitol NP-9 is chosen as surfactant (75\%). The synthesis was performed at $50^{\circ} \mathrm{C}$ with a reaction time of $2 \mathrm{~h}$. Final particles are all rod-shaped with approximate dimensions of $60 \times 60 \times 200 \mathrm{~nm}^{3}$. TEM, powder X-ray diffraction and magnetic measurements confirm their exact nature and the SCO features (see ESI).

$\S \S$ AuNPs were synthesized by previous reported protocols in the literature. ${ }^{10}$ A surface functionalization step was carried out after the synthesis for all the AuNPs sizes. The subsequent initial protecting ligand of the AuNPs will be replaced by the PVP polymer (MW=55000). Samples will be purified from the 
PVP excess by using centrifugation. Finally, AuNPs@PVP will be redispersed in $\mathrm{EtOH}$. The quality of the particles and their dimensions were checked by UV-Vis spectroscopy and TEM images (see ESI).

Acknowledgements are due to the Conseil Régional d'Aquitaine for the PhD grants of L.M and to the ANR agency (project ANR-11-BS08-06) for funding The microscopy was done in the Bordeaux Imaging Center of the University of Bordeaux. The help of Sabrina Lacomme is acknowledged.

1 (a) Spin-Crossover Materials: Properties and Applications, edited by M.A. Halcrow, 2013, John Wiley\&Sons; (b) S. Hayami, S.M. Holmes, M.A. Halcrow, J. Mater. Chem. C 2015, 3, 7775 and all included articles; (c) P. Gütlich, A.B. Gaspar, Y. Garcia, Beilstein J. Org. Chem. 2013, 9, 342; (d) A Bousseksou, G. Molnár, L. Salmon, W. Nicolazzi, Chem. Soc. Rev., 2011, 40, 3313; e) K.S. Murray, H. Oshio, J.A. Real Eur. J. Inorg. Chem. 2013, 577 and all included articles; (e) Eds. P. Gütlich, and H. A. Goodwin, Spin crossover in Transition Metal Compounds, Topics in Current Chemistry, Springer-Verlag Berlin Heidelberg NewYork 2004, volumes I, II and III. (a) O. Kahn, J. Kröber, C. Jay, Advanced Materials, 1992, 4, 718; (b) O Kahn and C. Jay-Martinez, Science, 1998, 279, 44; (c) J.-F. Létard, P. Guionneau, L. Goux-Capes, Top. Curr. Chem., 2004, 235, 221.

3 (a) P.N. Martinho, C. Rajnak, M. Ruben, Spin-Crossover Materials: Properties and Applications, 1st ed.; Halcrow, M.A., Ed.; John Wiley \& Sons: City, UK, 2013; pp. 375-404. (b) A. Tissot, L. Rechignat, A. Bousseksou, M.L. Boillot, J. Mater. Chem. C, 2012, 22, 3411; (c) E. Coronado, J.R. Galán-Mascarós, M. Monrabal-Capilla, J. Garciá-Martinez, P. Pardo-lbañez, Advanced materials 2007, 19, 1359; (d) T. Forestier, A. Kaiba, S. Pechev, D. Denux, P. Guionneau, C. Etrillard, N. Daro, E. Freysz, J.-F Létard, Chemistry, a European Journal 2009, 15, 6122; (e) D. Mader, S. Pillet, C. Carteret, M.-J Stébé, J.-L. Blin, Journal of dispersion Science and Science and Technology, 2011, 32, 1771. (f) I. A. Gural'skiy, C.M. Quintero, G. Molnár, I. O. Fritsky, L. Salmon, A. Bousseksou, Chemistry a European Journal 2012, 18, 9946; (g) C. Bartual-Murgui, E. Natividad, O. Roubeau, Journal of Materials Chemistry C, 2015, 3, 7916.

4 (a) S. K. Ghosh, T. Pal, Chem. Rev., 2007, 107, 4797; (b) P. Durand, S. Pillet, E. Bendeif, C. Carteret, M. Bouazaoui, H. El Hamzaoui, B. Capoen, L. Salmon, S. Hébert, J. Ghanbaja, L. Arandah, D. Schaniel, J. Mater. Chem. C, 2013, 1, 1933.

5 (a) D. Qiu, L. Gu, X. -L. Sun, D. -H. Ren, Z.-G. Gu, Z. Lia, R. Soc. Chem. Adv. 2014, 4, 61313; (b) C. M. Quintero, G. Felix, I. Suleimanov, J. Sanchez Costa, G. Molnar, L. Salmon, W. Nicolazzi, A. Bousseksou, Beilstein J Nanotechnol., 2014, 5; (c) M. Gimenez-Marqués, M. Luisa Garcia-Sanz de Larrea, E. Coronado, J. Mater. Chem. C 2015, 3, 7946-7953 ; (d) C. BartualMurgui, E. Natividad, O. Roubeau, J. Mater. Chem. C 2015, 3, 7916-7924

6 (a) K. L. Kelly, E. Coronado, L.L. Zhao, G.C. Schatz, J. Phys. Chem. B, 2003 107, 668; (b) L. M. Liz-Marzan, Langmuir, 2006, 22, 32; (c) P. K. Jain, X Huang, I. H. El-Sayed and M. A. El-Sayed, Acc. Chem. Res., 2008, 41, 1578.

7 T. Forestier, S. Mornet, N. Daro, T. Nishihara, S.-I. Mouri, K. Tanaka, O. Fouché, E. Freysz and J.-F. Létard, Chem. Commun., 2008, 4327.

8 (a) J.G. Haasnoot, G. Vos, W.L. Groeneveld, Z. Naturforsch, 1977, 32b, 1421; (b) J. Kröber, J. P. Audière, R. Claude, E. Codjovi, O. Kahn, J.G. Haasnoot, F. Grolière, C. Jay, A. Bousseksou, J. Linarès, F. Varret, A. Gonthier-Vassal, Chem. Mater. 1994, 6, 1404; (c) G. Aromi, L.A. Barros,
O. Roubeau, P. Gamez, Coord. Chem. Rev. 2011, 255, 485; (d) L. G. Lavrenova, O. G. Shakirova, Eur. J. Inorg. Chem., 2013, 670.

9 (a) L. Moulet, N. Daro, C. Etrillard, J.-F Létard, A. Grosjean, P. Guionneau Magnetochemistry, 2016, 2(1), 10; doi:10.3390/ magnetochemistry201001; (b) A. Grosjean, P. Négrier, P. Bordet, C. Etrillard, D. Mondieig, S. Pechev, E. Lebraud, J.-F. Létard and P. Guionneau, Eur. J. Inorg. Chem. 2013, 796; (c) A. Grosjean, N. Daro, S. Pechev; L. Moulet, C. Etrillard, G. Chastanet, P. Guionneau, Eur. J. Inorg. Chem., 2016, 1961.

10 (a) N. R. Jana, L. Gearheart, C. J. Murphy, J. Phys. Chem. B., 2001, 105, 4065; (b) N. G. Bastus, J. Comenge, V. Puntes, Langmuir, 2011, 27, 11098.

11 Li, N.; Zhao, P.; Liu, N.; Moya, S.; Salmon, L.; Ruiz, J.; Astruc, D. Chem.-Eur. J., 2014, 20, 8363 . 